\title{
Analysis and Performance with Vertical Divided Multilevel Voltage on Phase of Induction Engine
}

\author{
Erol CAN
}

\begin{abstract}
In this study, the quality of the transformed energy form is analysed after comparing the single-phase induction motor operated by the SPWM inverter to the 15level LPWM inverter. Firstly, multilevel inverter and pulse width modulation are designed. The multi-level inverter has sixteen IGBT switches because inverter circuit is constructed with high multilevel inverter topology. Linear pulse width modulation (LPWM) is designed for operation of sixteen switches in the inverter circuit. Secondly, equations of the induction motor are calculated according to $d$-q axis with creating 15 -level alternating voltage. After described equations, 15-level inverter running single phase induction motor is formed at the Matlab Simulink. The obtained results are analyzed according to motor performance and harmonic distortion of the created alternating energy after the proposed model is simulated. Finally, Simulation results of the proposed system are compared with simulation results of SPWM inverter controlling the single-phase induction motor.
\end{abstract}

Keywords: $d-q$ axis; harmonic; high multilevel inverter; linear pulse width modulation; quality of converted energy

\section{INTRODUCTION}

Electric machines and their driver systems providing transformation of energy have been used widely in industry and social life such as marketing, agricultural works. So, there were the scientific studies on systems of electric machine driver and energy conversion [1-8]. The asynchronous machine is very important for power providing in industry, agricultural works, because it is cheap and available [9-12]. Inverter systems have to be used so that asynchronous machine can be driven with energy conversion. Some papers have presented a lot of inverter topologies such as full bridge half bridge $[1,2]$. While multilevel inverter was investigated, pulse width modulations were widely used for operations of the switches on inverter [13-15]. In the study, a different approaching is presented with 15 -level inverter for single phase asynchronous machine driving. In inverter construction stage, 16 power switches are used such as IGBTs. So, linear pulse width modulation (LPWM) is considered for operation of the switches on 15-level inverter. The alternating voltage on the load can be divided into vertically equal electrical angles by the proposed PWM method. The voltage levels on the load are formed as horizontal pieces with different electrical angles in previous inverter studies such as $[5,9]$ while the voltage levels created on the load by the proposed method are composed of vertical pieces with equal electrical angles. This provides mathematical equations to be calculated with equal electrical angles on $360^{\circ}$ of electrical angle. The mathematical equations are given in section 2.2 after the LPWM controlling the structure and switches of the inverter are given in section 2.1. After that, simulation model of the LPWM 15-level inverter driving induction motor is constructed and performed at the Matlab Simulink. After performance of the proposed inverter system in simulation is compared with the performance of SPWM inverter driving induction motor which is auxiliary winding current, main winding current, rotor speed, electromagnetic torque and harmonic distortion in capacitor-start operation, the analysis is made. So, the harmonic distortion percentages of currents generated in section 3 are given by tables and graphs. With the proposed inverter structure, the harmonic distortion of some electrical angles, which are h8, h12, h13, h14 close to zero. This leads to a reduction of the deterioration of most of the alternating current generated. The performance of the LPWM inverter system running induction motor with converting alternating energy is acceptable because obtained results include total harmonic distortion lower than $4 \%$ and the current distortion of SPWM inverter running induction motor.

\section{15-LEVEL INVERTER SYSTEM}

\subsection{Linear Pulse Width Modulation (LPWM)}

For 15-Level Inverter, Pulse width modulation is considered as good choosing for application of switching function inverter [13, 16]. Although there are some inverter topologies for energy regulating and load, high multilevel inverter topology is used in the paper. The 15level inverter in high multilevel inverter topology uses linear pulse width modulation which is created with 26 triangle signals comparing with one constant signal as shown in Fig. 1. Created LPWM controls IGBT switches on the full bridge of 15-level inverter that is from I0 to I15 as shown in Fig. 2.
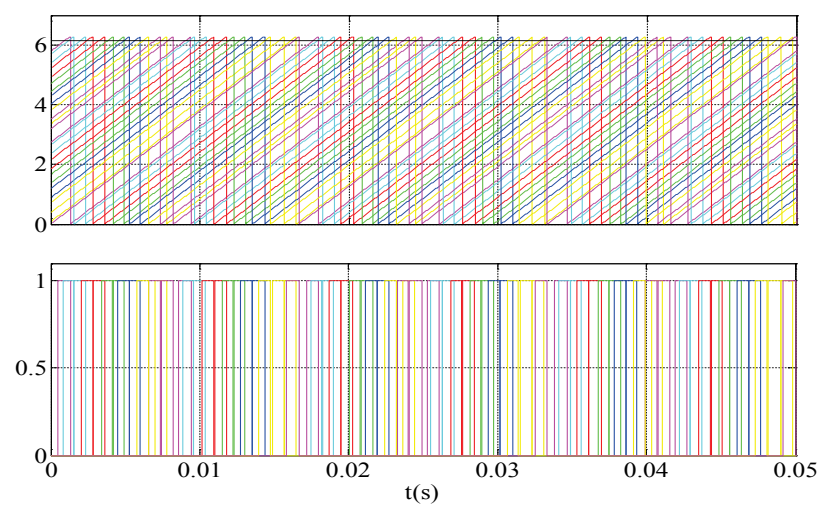

Figure 1 Linear pulse width modulation for 15 -level inverter 


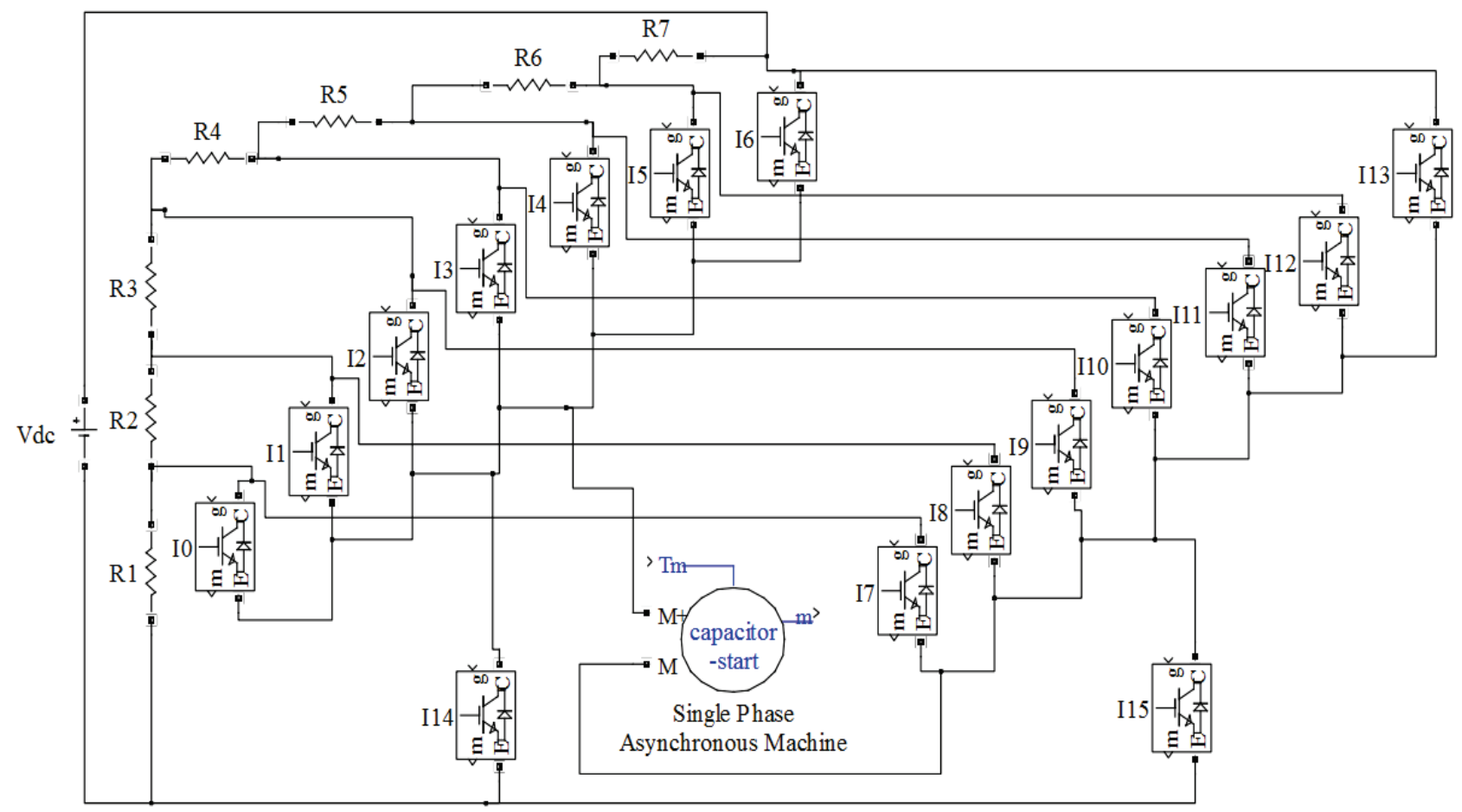

Figure 2 Full bridge of the 15 -level inverter according to high multilevel inverter

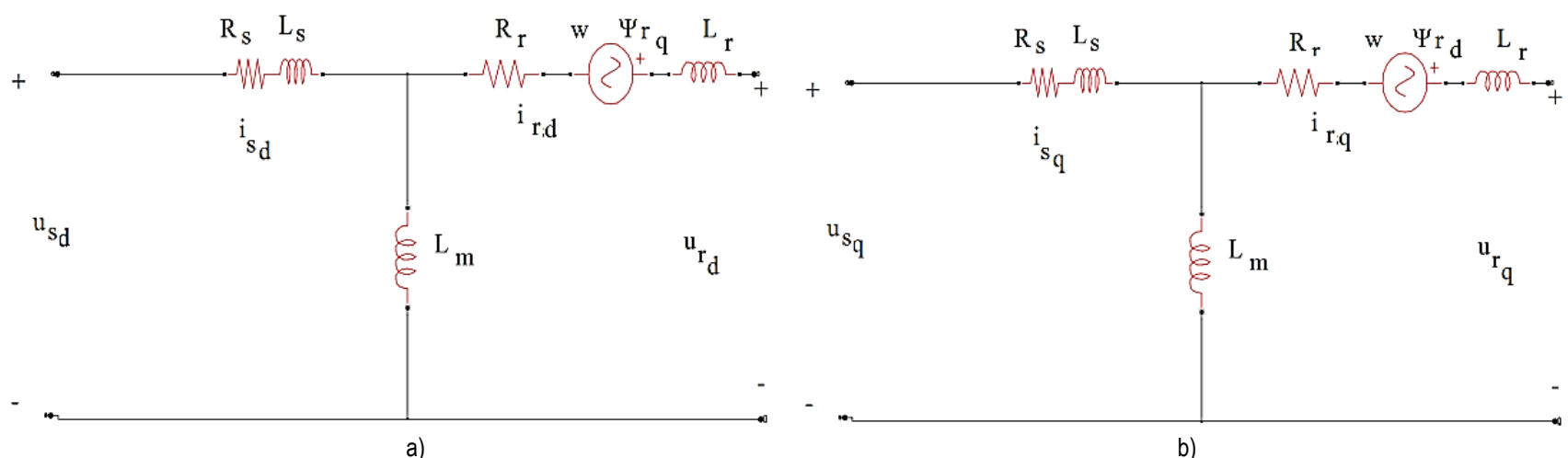

Figure 3 a) $d$-axis equivalent circuit of induction motor, b) $q$-axis equivalent circuit of induction motor

\subsection{Single Phase Asynchronous Machine}

The asynchronous machine is crucial for power providing in scientific works because it is cheap, durable and available. Single phase induction motor includes two windings as the main and auxiliary windings. The model can provide for simulating the capacitor-start, and main \& auxiliary winding operation modes. All stator and rotor quantities in the stator reference frame $(d-q$ frame) are described with seven parts because divided and known alternating voltage is created on the phase of a synchronous machine.

The stator reference frame in $d$ and $q$ axis is given in Fig. 3. $\psi_{s d}$ is the stator d axis flux, $\psi_{s q}$ is the stator $q$ axis flux, $\psi_{r d}$ is the rotor d axis flux, $\psi_{r q}$ is the rotor $q$ axis flux, $u_{s d}$ is $d$ axis of the stator voltage, $u_{s q}$ is $q$ axis of the stator voltage, $u_{r d}$ is $d$ axis of the rotor voltage, $u_{r q}$ is $q$ axis of the rotor voltage, $i_{s d}$ is the stator $d$ axis current, $i_{s q}$ is the stator $q$ axis current, $i_{r d}$ is the rotor $\mathrm{d}$ axis current, $i_{r q}$ is the rotor $q$ axis current. $R_{s}$ is the stator resistance, $L_{m}$ is the magnetizing inductance, $L_{s}$ is the stator inductance, $R_{r}$ is the stator resistance, $L_{r}$ is the rotor inductance.
$1 / 7$ of DC voltage source is employed for one-level of an alternating voltage. Then, $q-d$ axis fluxes of stator and $q$ and $d$ axis fluxes of a rotor are in Eq. (1), Eq. (2), Eq. (3), Eq. (4) while I0-I15-I7-I14 are operating on $12^{\circ}$ $24^{\circ} ; 168^{\circ}-180^{\circ} ; 192^{\circ}-204^{\circ} ; 348^{\circ}-360^{\circ}$ of electrical angles.

$$
\begin{aligned}
& \Psi_{s q 1}=2 L_{s} i_{s q 1}+2 L_{m} i_{r q 1} \\
& \Psi_{s d 1}=2 L_{s} i_{s d 1}+2 L_{m} i_{r d 1} \\
& \Psi_{r q 1}=2 L_{r} i_{r q 1}+2 L_{m} i_{s q 1} \\
& \Psi_{r d 1}=2 L_{r} i_{r d 1}+2 L_{m} i_{s d 1}
\end{aligned}
$$

2/7 of DC voltage source is employed for two-level of an alternating voltage. Then, $q-d$ axis fluxes of stator and $q$ and $d$ axis fluxes of a rotor are in Eq. (5), Eq. (6), Eq. (7), Eq. (8) while I1-I15-I8-I14 are operating on $24^{\circ}$ $36^{\circ} ; 156^{\circ}-168^{\circ} ; 204^{\circ}-216^{\circ} ; 336^{\circ}-348^{\circ}$ of electrical angles.

$\Psi_{s q 2}=4 L_{s} i_{s q 1}+4 L_{m} i_{r q 1}$ 


$$
\begin{aligned}
& \Psi_{S d 2}=4 L_{s} i_{s d 1}+4 L_{m} i_{r d 1} \\
& \Psi_{r q 2}=4 L_{r} i_{r q 1}+4 L_{m} i_{s q 1} \\
& \Psi_{r d 2}=4 L_{r} i_{r d 1}+4 L_{m} i_{s d 1}
\end{aligned}
$$

3/7 of DC voltage source is employed for three-level of alternating voltage. Then, $q$ and $d$ axis fluxes of stator and $q$ and $d$ axis fluxes of rotor are in Eq. (9), Eq. (10), Eq. (11), Eq. (12) while I2-I15-I9-I14 are operating on $36^{\circ}-48^{\circ} ; 144^{\circ}-156^{\circ} ; 216^{\circ}-228^{\circ} ; 324^{\circ}-336^{\circ}$ of electrical angles.

$$
\begin{aligned}
& \Psi_{s q 3}=6 L_{s} i_{s q 1}+6 L_{m} i_{r q 1} \\
& \Psi_{s d 3}=6 L_{s} i_{s d 1}+6 L_{m} i_{r d 1} \\
& \Psi_{r q 3}=6 L_{r} i_{r q 1}+6 L_{m} i_{s q 1} \\
& \Psi_{r d 3}=6 L_{r} i_{r d 1}+6 L_{m} i_{s d 1}
\end{aligned}
$$

4/7 of DC voltage source is employed for four-level of the alternating voltage. Then, $q$ and $d$ axis fluxes of the stator and $q$ and $d$ axis fluxes of the rotor are in Eq. (13), Eq. (14), Eq. (15), Eq. (16) while I3-I15-I10-I14 are operating on $48^{\circ}-60^{\circ} ; 132^{\circ}-144^{\circ} ; 228^{\circ}-240^{\circ} ; 312^{\circ}-324^{\circ}$ of electrical angles.

$$
\begin{aligned}
& \Psi_{s q 4}=8 L_{s} i_{s q 1}+8 L_{m} i_{r q 1} \\
& \Psi_{s d 4}=8 L_{s} i_{s d 1}+8 L_{m} i_{r d 1} \\
& \Psi_{r q 4}=8 L_{r} i_{r q 1}+8 L_{m} i_{s q 1} \\
& \Psi_{r d 4}=8 L_{r} i_{r d 1}+8 L_{m} i_{s d 1}
\end{aligned}
$$

$5 / 7$ of DC voltage source is employed for five-level of the alternating voltage. Then, $q-d$ axis fluxes of the stator and $q$ and $d$ axis fluxes of the rotor are in Eq. (17), Eq. (18), Eq. (19), Eq. (20) while I4-I15-I11-I14 are operating on $72^{\circ}-84^{\circ} ; 120^{\circ}-132^{\circ} ; 252^{\circ}-264^{\circ} ; 300^{\circ}-312^{\circ}$ of electrical angles.

$$
\begin{aligned}
& \Psi_{s q 5}=10 L_{s} i_{s q 1}+10 L_{m} i_{r q 1} \\
& \Psi_{s d 5}=10 L_{s} i_{s d 1}+10 L_{m} i_{r d 1} \\
& \Psi_{r q 5}=10 L_{r} i_{r q 1}+10 L_{m} i_{s q 1} \\
& \Psi_{r d 5}=10 L_{r} i_{r d 1}+10 L_{m} i_{s d 1}
\end{aligned}
$$

6/7 of DC voltage source is employed for six-level of the alternating voltage. Then, $q$ and $d$ axis fluxes of stator and $q$ and $d$ axis fluxes of the rotor are in Eq. (21), Eq. (22), Eq. (23), Eq. (24) while I4-I15-I12-I14 are operating on $84^{\circ}-96^{\circ} ; 108^{\circ}-120^{\circ} ; 264^{\circ}-276^{\circ} ; 288^{\circ}-300^{\circ}$ of electrical angles.

$$
\begin{aligned}
& \Psi_{s q 6}=12 L_{s} i_{s q 1}+12 L_{m} i_{r q 1} \\
& \Psi_{s d 6}=12 L_{s} i_{s d 1}+12 L_{m} i_{r d 1} \\
& \Psi_{r q 6}=12 L_{r} i_{r q 1}+12 L_{m} i_{s q 1} \\
& \Psi_{r d 6}=12 L_{r} i_{r d 1}+12 L_{m} i_{s d 1}
\end{aligned}
$$

7/7 of DC voltage source is employed for seven-level of alternating voltage. Then, $q$ and $d$ axis fluxes of stator and $q$ and $d$ axis fluxes of rotor are in Eq. (25), Eq. (26),
Eq. (27), Eq. (28) while I6-I15-I13-I14 are operating on $96^{\circ}-108^{\circ} ; 276^{\circ}-288^{\circ}$.

$$
\begin{aligned}
& \Psi_{s q 7}=14 L_{s} i_{s q 1}+14 L_{m} i_{r q 1} \\
& \Psi_{s d 7}=14 L_{s} i_{s d 1}+14 L_{m} i_{r d 1} \\
& \Psi_{r q 7}=14 L_{r} i_{r q 1}+14 L_{m} i_{s q 1} \\
& \Psi_{r d 7}=14 L_{r} i_{r d 1}+14 L_{m} i_{s d 1}
\end{aligned}
$$

Stator and rotor voltages in $d$ axis are formed with considering values of first step level as in Eq. (29) and Eq. (30).

$$
\begin{aligned}
& u_{s d}=R_{s} 2 \sum_{k=1}^{7}\left(i_{s d 1}\right) k+2 \sum_{k=1}^{7}\left(\frac{\mathrm{d}}{\mathrm{d} t} \Psi_{s d 1}\right) k \\
& u_{r d}=R_{r} 2 \sum_{k=1}^{7}\left(i_{r d 1}\right) k+2 \sum_{k=1}^{7}\left(\frac{\mathrm{d}}{\mathrm{d} t} \Psi_{r d 1}\right) k+w 2 \sum_{k=1}^{7}\left(\Psi_{r d 1}\right) k
\end{aligned}
$$

Stator and rotor voltages in $q$ axis are formed with considering values of first step level as in Eq. (31) and Eq. (32).

$$
\begin{aligned}
& u_{s q}=R_{s} 2 \sum_{k=1}^{7}\left(i_{s q 1}\right) k+2 \sum_{k=1}^{7}\left(\frac{\mathrm{d}}{\mathrm{d} t} \Psi_{s q 1}\right) k \\
& u_{r q}=R_{r} 2 \sum_{k=1}^{7}\left(i_{r q 1}\right) k+2 \sum_{k=1}^{7}\left(\frac{\mathrm{d}}{\mathrm{d} t} \Psi_{r q 1}\right) k-w 2 \sum_{k=1}^{7}\left(\Psi_{r q 1}\right) k
\end{aligned}
$$

If rotor voltages and stator voltages in $d$ and $q$ axis are transformed to $a$ axis according to third level voltage, Eq. (33) and Eq. (34) are obtained. Relation of $a, b$ axis to $d, q$ axis is shown in Fig. 4.

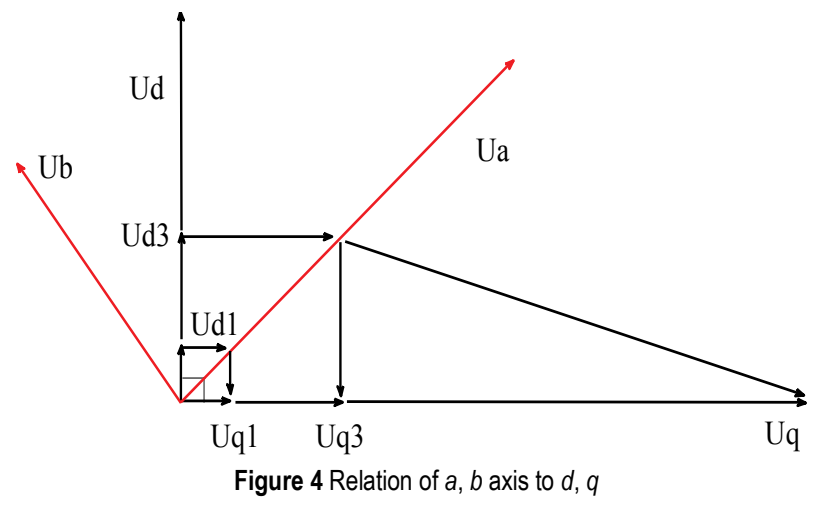

$$
\begin{aligned}
& {\left[u_{s a}\right]^{2}=\left[R_{s} 2 \sum_{k=1}^{3}\left(i_{s q 1}\right) k+2 \sum_{k=1}^{3}\left(\frac{\mathrm{d}}{\mathrm{d} t} \Psi_{s q 1}\right) k\right]^{2}+} \\
& +\left[R_{s} 2 \sum_{k=1}^{3}\left(i_{s d 1}\right) k+2 \sum_{k=1}^{3}\left(\frac{\mathrm{d}}{\mathrm{d} t} \Psi_{s d 1}\right) k\right]^{2} \\
& {\left[u_{r a}\right]^{2}=\left[R_{r} 2 \sum_{k=1}^{3}\left(i_{r q 1}\right) k+2 \sum_{k=1}^{3}\left(\frac{\mathrm{d}}{\mathrm{d} t} \Psi_{r q 1}\right) k-w 2 \sum_{k=1}^{3}\left(\Psi_{r q 1}\right) k\right]^{2}+} \\
& +\left[R_{r} 2 \sum_{k=1}^{3}\left(i_{r d 1}\right) k+2 \sum_{k=1}^{3}\left(\frac{\mathrm{d}}{\mathrm{d} t} \Psi_{r d 1}\right) k+w 2 \sum_{k=1}^{3}\left(\Psi_{r d 1}\right) k\right]^{2}
\end{aligned}
$$




\section{SIMULATION OF 15-LEVEL INVERTER DRIVING INDUCTION MOTOR}

The simulation model of single-phase asynchronous motor is constructed with the 15-level inverter in capacitor-start-mode in order to investigate the performance characteristics as in Fig. 5. After that, observed results of the proposed system are compared with the known and accepted performance of SPWM inverter. The motor is rated 1/4 HP, $110 \mathrm{~V}, 60 \mathrm{~Hz}, 1800$ rpm.

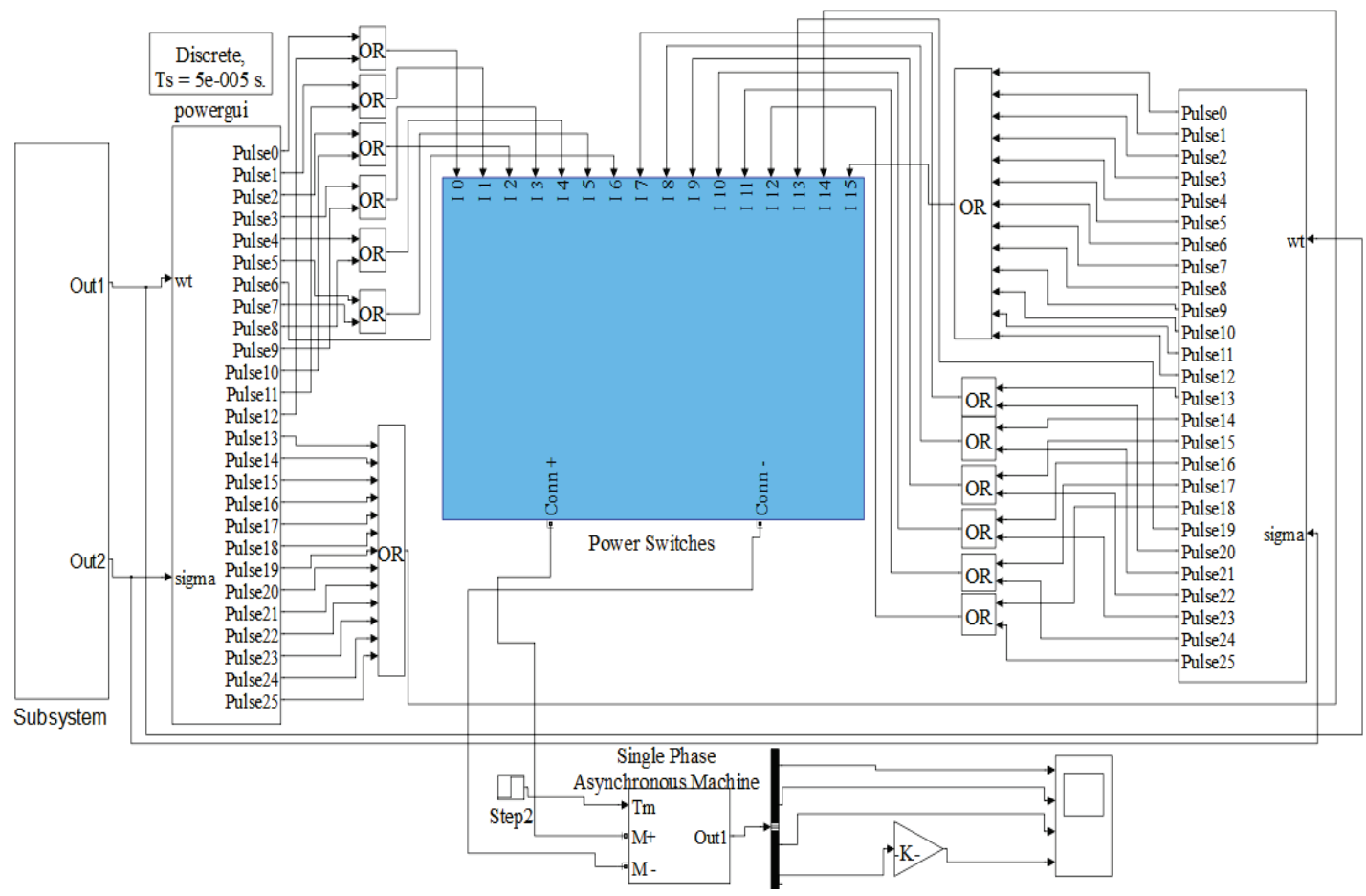

Figure 5 15-level inverter driving induction motor

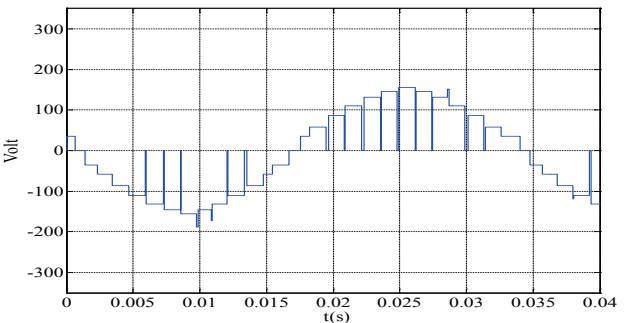

a)

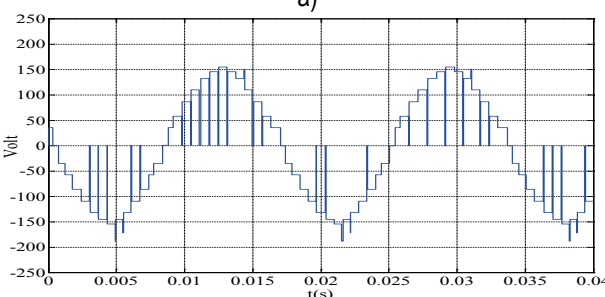

b)

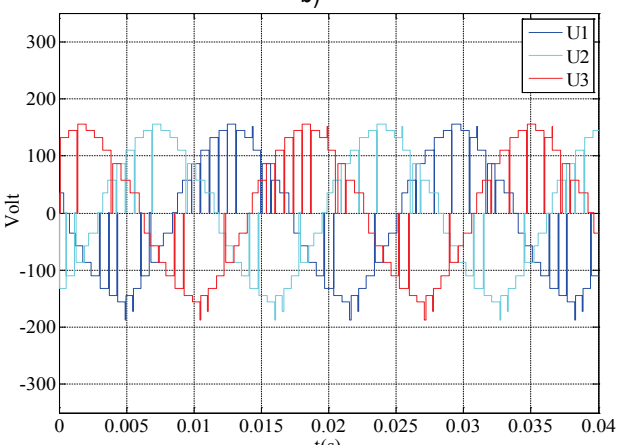

)

Figure 6 a) 15-level alternating voltage for $30 \mathrm{~Hz}$, b) 15-level alternating voltage for $60 \mathrm{~Hz}, \mathrm{c}$ ) 3-phase of 15-level alternating voltage for $60 \mathrm{~Hz}$
Unfiltered alternating voltages form for the phase of induction machine on 15-level as shown in Fig. 6. The created alternating voltage which is different in other studies on the 15-level has experimented in order to run induction motor with demanded performance.

15-level alternating voltages formed on different frequencies such as $30 \mathrm{~Hz}$ and $60 \mathrm{~Hz}$ in Fig. 6. 3-phase alternating voltage with 60 -degree phase difference is given in Fig. 6c. Main Winding Currents of two inverters driving induction motor in capacitor-start operation mode are given in Fig. 7.

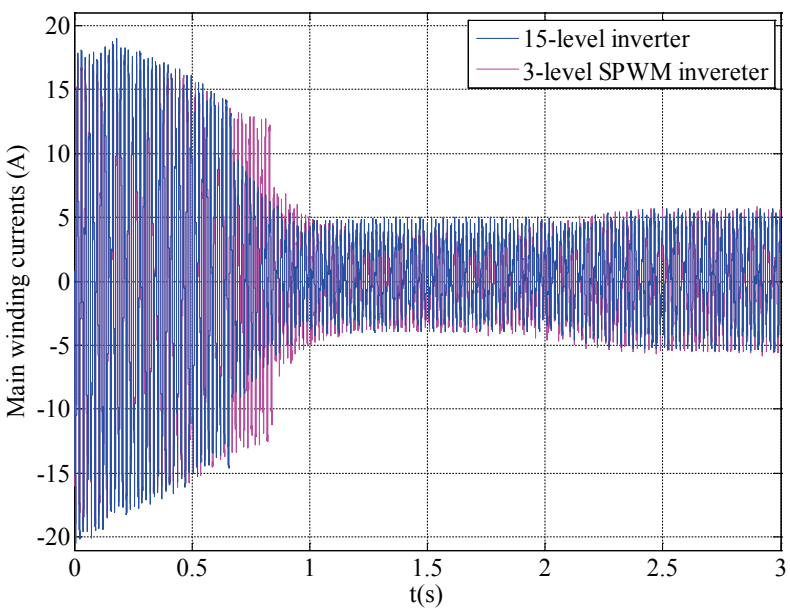

Figure 7 Main Winding Currents of two inverters driving induction motor

The current of main winding starts to settle for the 15-level inverter on $0.625 \mathrm{~s}$ while settling for SPWM 
inverter on $0.825 \mathrm{~s}$. For the main winding current of the 15 -level inverter, the settling time to the steady state is shorter. There is a small increase in torque to keep the rotor speed constant, which tends to decline at $2 \mathrm{~s}$ due to load. Capacitor voltages of two inverters driving induction motor in capacitor-start operation mode are given in Fig. 8.

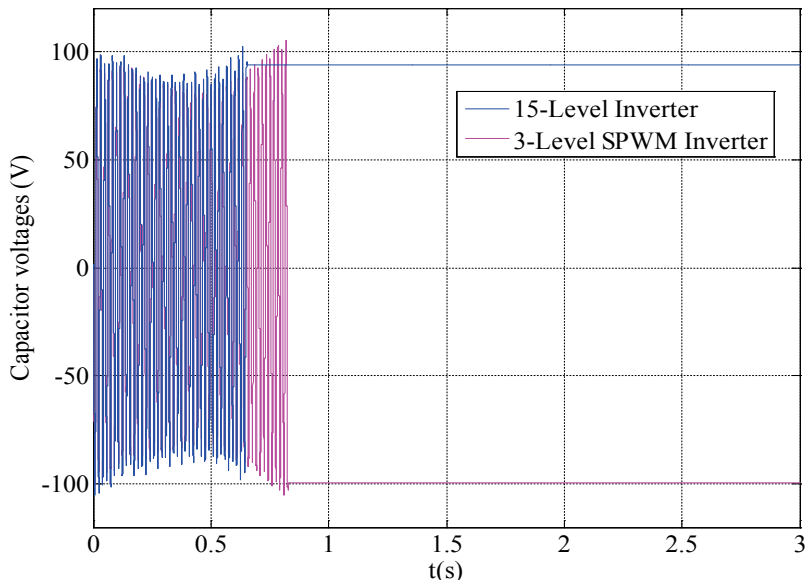

Figure 8 Capacitor voltages of two inverters driving induction motor

The capacitor voltage is settling for the 15-level inverter on +90 volt while settling for SPWM inverter on90 volt. For capacitor voltage of the 15 -level inverter, the settling time to the steady state is shorter on the maximum value. Rotor speeds and auxiliary winding currents of two inverters driving induction motor in capacitor-start operation mode are given in Fig. 9 and in Fig. 10.

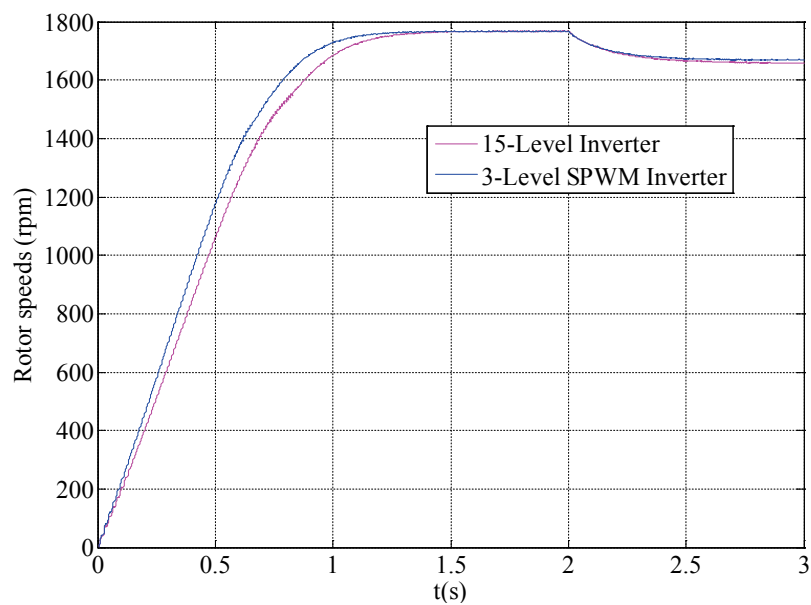

Figure 9 Rotor speeds of two inverters driving induction

Since different modulation and inverter models are used, there are some voltage differences on the load, which causes changes in rotor speed. The auxiliary winding current of the 15-level inverter is set to zero when the speed reaches $1400 \mathrm{rpm}$ on $0.625 \mathrm{~s}$. The auxiliary winding current of SPWM inverter is set to zero when the speed reaches $1525 \mathrm{rpm}$ on $0.825 \mathrm{~s}$. According to these results, the rotor accelerates more quickly and becomes steady in the proposed method.

Electromagnetic torques of two inverters driving induction motor in capacitor-start operation mode is given in Fig. 11.

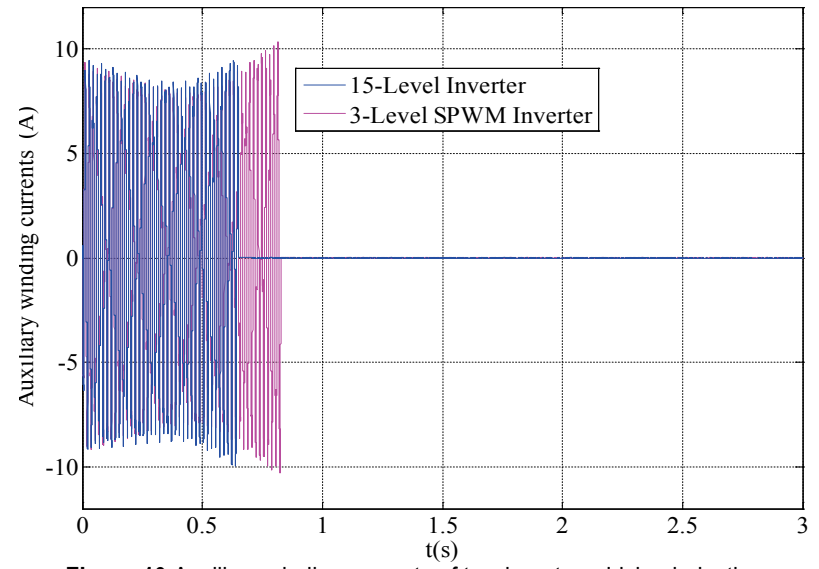

Figure 10 Auxiliary winding currents of two inverters driving induction

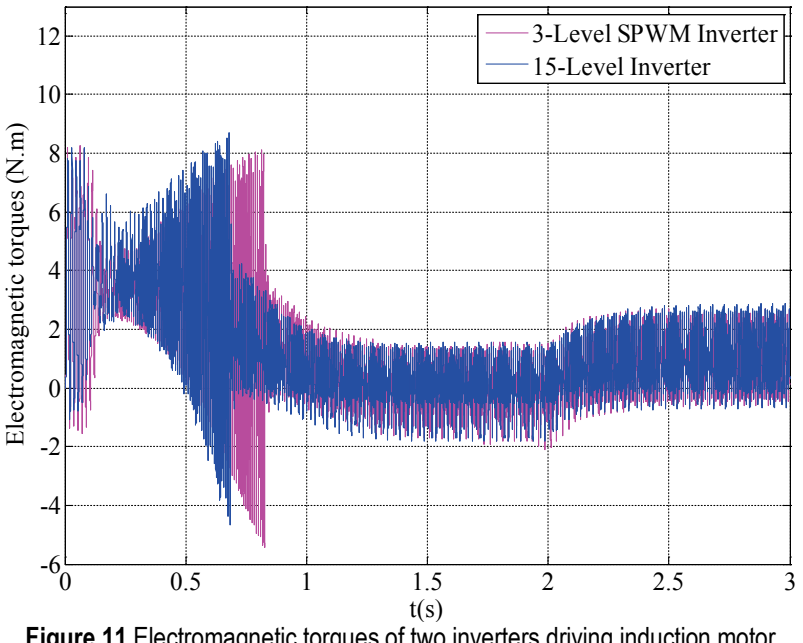

Figure 11 Electromagnetic torques of two inverters driving induction motor

The electromagnetic torque of 15 -level inverter is reaching the maximum value as $8.4 \mathrm{~N} \cdot \mathrm{m}$ on $0.625 \mathrm{~s}$ before settling first part of the steady state. The electromagnetic torque of SPWM inverter is reaching the maximum value as $8 \mathrm{~N} \cdot \mathrm{m}$ on $0.825 \mathrm{~s}$ before settling first part of the steady state.

Total harmonic distortion of phase current is given in Fig. 12 and in Tab. 1 after SPWM inverter operating induction motor.

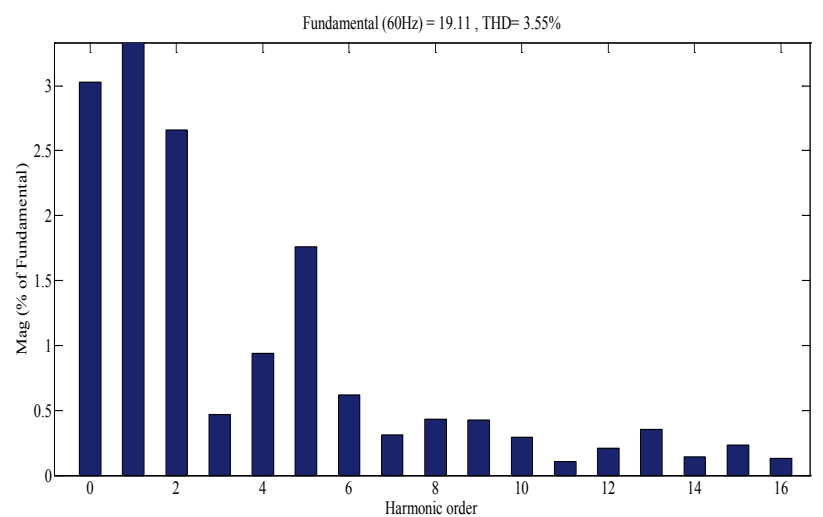

Figure 12 Total harmonic distortion of phase current for SPWM inverter

Harmonic order of phase current for SPWM inverter is given in Fig. 13. H1 is a fundamental value for $60 \mathrm{~Hz}$. Sampling time is $5 \mathrm{e}-005 \mathrm{~s}$, samples per cycle is 333.333 , fundamental is 19.21 peak (13.58 rms), Total Harmonic Distortion (THD) is $3.55 \%$. The maximum harmonic 
frequency used for THD calculation is $9900.00 \mathrm{~Hz}\left(165^{\text {th }}\right.$ harmonic) in Tab. 1.

Table 1 Total harmonic distortion of phase current for SPWM inverter

\begin{tabular}{|c|c|c|c|}
\hline Harmonic Order & Frequencies & Harmonic & $\begin{array}{c}\text { Electrical } \\
\text { angles }\end{array}$ \\
\hline (Fnd): & $60 \mathrm{~Hz}$ & $100.00 \%$ & $0.0^{\circ}$ \\
\hline (H2): & $120 \mathrm{~Hz}$ & $2.66 \%$ & $34.5^{\circ}$ \\
\hline (H3): & $180 \mathrm{~Hz}$ & $0.56 \%$ & $211.9^{\circ}$ \\
\hline$(\mathrm{H} 4):$ & $240 \mathrm{~Hz}$ & $0.92 \%$ & $129.6^{\circ}$ \\
\hline$(\mathrm{H} 5):$ & $300 \mathrm{~Hz}$ & $1.69 \%$ & $52.5^{\circ}$ \\
\hline (H6): & $360 \mathrm{~Hz}$ & $0.63 \%$ & $199.5^{\circ}$ \\
\hline$(\mathrm{H} 7):$ & $420 \mathrm{~Hz}$ & $0.37 \%$ & $164.4^{\circ}$ \\
\hline$(\mathrm{H} 8):$ & $480 \mathrm{~Hz}$ & $0.41 \%$ & $2.8^{\circ}$ \\
\hline$(\mathrm{H} 9):$ & $540 \mathrm{~Hz}$ & $0.37 \%$ & $205.3^{\circ}$ \\
\hline (H10): & $600 \mathrm{~Hz}$ & $0.28 \%$ & $208.0^{\circ}$ \\
\hline (H11): & $660 \mathrm{~Hz}$ & $0.08 \%$ & $90.7^{\circ}$ \\
\hline (H12): & $720 \mathrm{~Hz}$ & $0.21 \%$ & $0.0^{\circ}$ \\
\hline (H13): & $780 \mathrm{~Hz}$ & $0.35 \%$ & $241.0^{\circ}$ \\
\hline (H14): & $840 \mathrm{~Hz}$ & $0.15 \%$ & $132.0^{\circ}$ \\
\hline (H15): & $900 \mathrm{~Hz}$ & $0.24 \%$ & $27.6^{\circ}$ \\
\hline (H16): & $960 \mathrm{~Hz}$ & $0.13 \%$ & $0.0^{\circ}$ \\
\hline
\end{tabular}

The maximum harmonic percentage is $2.66 \%$ for $\mathrm{h} 2$ when SPWM inverter creates the alternating voltage on $34.5^{\circ}$ of electrical angle as shown in Tab.1. h16 is minimum values of harmonic distortion with $0.13 \%$ while converting current is on $960 \mathrm{~Hz}$ and $0.0^{\circ}$ of electrical angle.

Total harmonic distortion of phase current is given in Fig. 13 and in Tab. 2 after 15-level inverter operating induction motor.

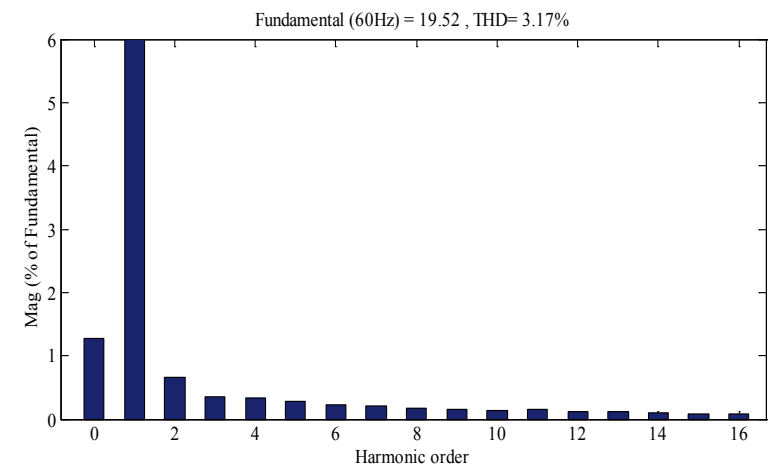

Figure 13 Total harmonic distortion of phase current for 15 -level inverter

Harmonic order of phase current for the 15-level inverter is given in Fig. 13. H1 is fundamental values for $60 \mathrm{~Hz}$.

Sampling time is 5e-005 s. Samples per cycle are 333.333. Fundamental is 19.05 peak (13.47 rms). Total Harmonic Distortion (THD) $=3.17 \%$.

The maximum harmonic frequency used for THD calculation is $9900.00 \mathrm{~Hz}\left(165^{\text {th }}\right.$ harmonic $)$ in Tab. 2.

The maximum harmonic percentage is $1.46 \%$ for $\mathrm{h} 2$ when SPWM inverter creates the alternating voltage at $0.0^{\circ}$ of electrical angle as shown in Tab. 2 . H15 is the minimum value of harmonic distortion with $0.06 \%$ while converting current is at $900 \mathrm{~Hz}$ and $166.8^{\circ}$ of electrical angle. Harmonic order of 15 -level inverter is given to compare with the harmonic order of SPWM inverter in Fig. 14.

Fig. 14b shows the distribution of the harmonics of the load currents of two different inverters according to their electrical angles. Fig. 14a shows the percentage values of harmonic orders.

Table 2 Total harmonic distortion of phase current for 15-level inverter

\begin{tabular}{|c|c|c|c|}
\hline $\begin{array}{c}\text { Harmonic } \\
\text { Order }\end{array}$ & Frequencies & Harmonic & $\begin{array}{c}\text { Electrical } \\
\text { angles }\end{array}$ \\
\hline (Fnd): & $60 \mathrm{~Hz}$ & $100.00 \%$ & $0.0^{\circ}$ \\
\hline (H2): & $120 \mathrm{~Hz}$ & $1.46 \%$ & $0.0^{\circ}$ \\
\hline (H3): & $180 \mathrm{~Hz}$ & $1.14 \%$ & $165.2^{\circ}$ \\
\hline (H4): & $240 \mathrm{~Hz}$ & $0.45 \%$ & $188.1^{\circ}$ \\
\hline (H5): & $300 \mathrm{~Hz}$ & $0.20 \%$ & $55.8^{\circ}$ \\
\hline (H6): & $360 \mathrm{~Hz}$ & $0.69 \%$ & $155.9^{\circ}$ \\
\hline (H7): & $420 \mathrm{~Hz}$ & $0.50 \%$ & $220.1^{\circ}$ \\
\hline (H8): & $480 \mathrm{~Hz}$ & $0.09 \%$ & $39.6^{\circ}$ \\
\hline (H9): & $540 \mathrm{~Hz}$ & $0.33 \%$ & $207.8^{\circ}$ \\
\hline (H10): & $600 \mathrm{~Hz}$ & $0.44 \%$ & $164.3^{\circ}$ \\
\hline (H11): & $660 \mathrm{~Hz}$ & $0.17 \%$ & $176.1^{\circ}$ \\
\hline (H12): & $720 \mathrm{~Hz}$ & $0.11 \%$ & $80.3^{\circ}$ \\
\hline (H13): & $780 \mathrm{~Hz}$ & $0.10 \%$ & $238.9^{\circ}$ \\
\hline (H14): & $840 \mathrm{~Hz}$ & $0.09 \%$ & $69.7^{\circ}$ \\
\hline (H15): & $900 \mathrm{~Hz}$ & $0.06 \%$ & $166.8^{\circ}$ \\
\hline (H16): & $960 \mathrm{~Hz}$ & $0.28 \%$ & $182.0^{\circ}$ \\
\hline
\end{tabular}

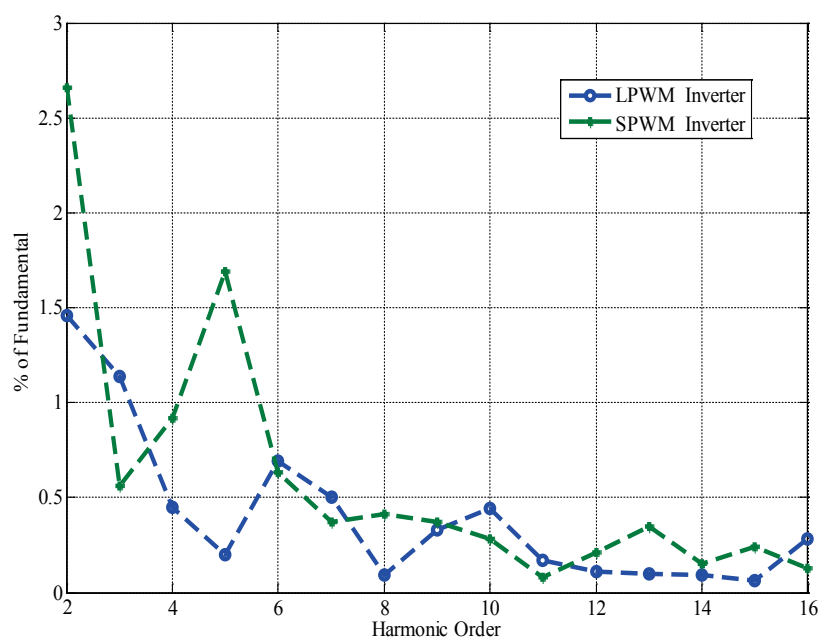

a)

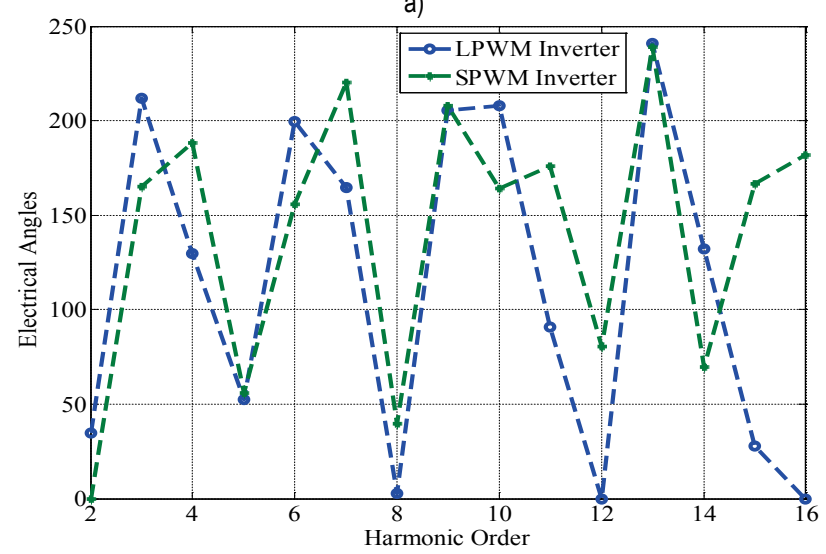

b)

Figure 14a) Comparing two harmonic orders b) harmonic orders according to electrical angles

Maximum harmonic percentage of the LPWM 15level inverter is $1.46 \%$ for $\mathrm{h} 2$ at $0.0^{\circ}$ of electrical angle while the maximum harmonic percentage of SPWM inverter is $2.66 \%$ for $\mathrm{h} 2$ at $34.5^{\circ}$ of electrical angle as shown in Fig. 14(a). H16 of the 15-level inverter is the minimum value of harmonic distortion with $0.13 \%$ at 960 $\mathrm{Hz}$ and $0.0^{\circ}$ of electrical angle while h15 of SPWM inverter is minimum value of harmonic distortion with $0.06 \%$ at $900 \mathrm{~Hz}$ and $166.8^{\circ}$ of electrical angle. While h5 
of the 15-level inverter reduces to $0.2 \%$ at $300 \mathrm{~Hz}$ and $55.8^{\circ}$ of electrical angle, H5 of the SPWM inverter increases to $1.69 \%$ at $300 \mathrm{~Hz}$ and $52.5^{\circ}$. The difference between the electrical angles of the $\mathrm{H} 12$ and $\mathrm{H} 16$ harmonics is the greatest, while the electrical angles of the $\mathrm{H} 3, \mathrm{H} 7$, and $\mathrm{H} 13$ harmonics of the load currents produced by the two inverters are very close to one another in fig. 14 (b). With the proposed inverter structure, the harmonic distortion of some electrical angles which are $\mathrm{h} 8, \mathrm{~h} 12, \mathrm{~h} 13, \mathrm{~h} 14$ reduces to zero while the conventional SPWM inverter method generally generates harmonics which are h2, h4, h5, h8, h9, h12, h13, h14, h15 at a higher level in most of the electrical angles. Hence, there is less deterioration in a greater proportion of the energy produced with LPWM inverter according to the conventional SPWM inverter method.

\section{CONCLUSIONS}

In this study, 15-level inverter and LPWM for inverter power switches are designed. The inverter system is adapted to single-phase induction motor driving. Therefore, the mathematical equations of the motor are created with the 15-level formation of the energy on the phase according to the $\mathrm{d}-\mathrm{q}$ axis. After that, proposed inverter system is simulated at the Matlab Simulink. Then, obtained results are compared with results of inverter system in previous works, which use SPWM. According to compared results, phase currents of the proposed inverter include lower harmonic distortion than the distortion of SPWM inverter phase current while the proposed method gives satisfactory results. So the singlephase induction motor can successfully be operated with a new approaching of multi-level inverter topology which provides partial analysis of voltage and current on equal electrical angles.

\section{REFERENCES}

[1] Tao, X. U. et al. (2016). Global synchronous discontinuous pulse width modulation method with fast calculation capability for distributed three-phase inverters. Journal of Modern Power Systems and Clean Energy, 4(1), 103-112. https://doi.org/10.1007/s40565-015-0180-5

[2] Yubo, Y. U. A. N. et al. (2016). Harmonic influence analysis of unified power flow controller based on modular multilevel converter. Journal of Modern Power Systems and Clean Energy, 4(1), 10-18. https://doi.org/10.1007/s40565-015-0175-2

[3] Ali, E. S. (2016). Imperialist competitive algorithm for speed control of induction motor supplied by wind turbine. ElectrEng, 98(2), 179-187. https://doi.org/10.1007/s00202-015-0353-2

[4] Taghvaie, A.; Adabi, J.; \& Rezanejad, M. (2016). Circuit Topology and Operation of a Step-Up Multilevel Inverter with a Single DC Source. IEEE Transactions on Industrial Electronics, 63(11), 6643-6652. https://doi.org/10.1109/TIE.2016.2585568

[5] Liu, J.; Sun, Y.; Li, Y.; \& Fu, C. (2016). Theoretical harmonic analysis of cascaded $\mathrm{H}$-bridge inverter under hybrid pulse width multilevel modulation. IET Power Electronics, 9(14), 2714-2722. https://doi.org/10.1049/iet-pel.2016.0163

[6] Can, E. (2017). Novel high multilevel inverters investigated on simulation. Electrical Engineering, 99(2), 633-638. https://doi.org/10.1007/s00202-016-0396-z
[7] Can, E. \& Sayan, H. H. (2018). A novel SSPWM controlling inverter running nonlinear device. Electrical Engineering, 100(1), 39-46. https://doi.org/10.1007/s00202-016-0480-4

[8] Ho, Anh-V. \& Tae-Won, C. (2016). Topologies of ActiveSwitched Quasi-Z-source Inverters with High-Boost Capability. Journal of Power Electronics, 16(5), 17161724. https:// doi.org/10.6113/JPE.2016.16.5.1716

[9] Andresen, E. Ch. \& Keller, R. (1997). Variable speed drive with current source inverter supply and permanent magnet synchronous motor compared with cage induction motor. Electrical engineering, 80(6), 375-381. https://doi.org/10.1007/BF01232927

[10] Subrahmanyam, D.; Subrahmanyam, V.; \& Rao, M. V. C. (1977). On the steady-state analysis of the inverter-fed induction motor. Archiv für Elektrotechnik, 59(6), 337-343. https://doi.org/10.1007/BF01578221

[11] Schreier, L.; Bendl, J.; \& Chomat, M. (2015). Effect of higher spatial harmonics on properties of six-phase induction machine fed by unbalanced voltages. ElectrEng, 97, 155-164. https://doi.org/10.1007/s00202-014-0319-9

[12] Saavedra, H.; Riba, J.-R.; \& Romeral, L. (2014). Detection of Inter-turn Faults in Five-Phase Permanent Magnet Synchronous Motors. Advances in Electrical and Computer Engineering, 14(4), 49-54. https://doi.org/10.4316/AECE.2014.04008

[13] Can, E. \& Sayan, H. H. (2016). PID and fuzzy controlling three phase asynchronous machine by low level DC source three phase inverter. Tehnicki vjesnik, 23(3), 753-760. https://doi.org/10.17559/TV-20150106105608

[14] Can, E. \& Sayan, H. H. (2016). SSPWM Three Phase Inverter Design and Experimented on Unbalanced Loads. Tehnicki vjesnik, 23(5), 1239-1244. https://doi.org/10.17559/TV-20150730222021

[15] Tao, X. U. et al. (2016). Global synchronous discontinuous pulse width modulation method with fast calculation capability for distributed three-phase inverters. Journal of Modern Power Systems and Clean Energy, 4(1), 103-112. https://doi.org/10.1007/s40565-015-0180-5

[16] Xavier, L. S.; Cupertino, A. F.; de Resende, J. T.; Mendes, V. F.; \& Pereira, H. A. (2017). Adaptive current control strategy for harmonic compensation in single-phase solar inverters. Electric Power Systems Research, 142, 84-95. https://doi.org/10.1016/j.epsr.2016.08.040

\section{Contact information:}

\section{Dr. Erol CAN}

Department of Aircraft Airframe and Power Plant,

School of Civil Aviation, Erzincan University,

Fatih Mahallesi, 24100 Erzincan, Turkey

E-mail: can_e@hotmail.com 